\title{
CHALLENGES FOR SELF-RECOVERY FROM CYCLONE DISASTERS IN A TRADITIONAL FIJIAN VILLAGE: THE CASE OF NAVALA VILLAGE AFTER TROPICAL CYCLONE WINSTON
}

\author{
MARI MIYAJ, AYAKO FUJIEDA, SAINIMERE VEITATA WAQALEVU \& HIROHIDE KOBAYASHI \\ Kyoto University, Japan
}

\begin{abstract}
Fiji is often affected by cyclones because of its geographic conditions. In February 2016, Fiji was hit by Tropical Cyclone Winston, the biggest cyclone to occur in the region in the last 20 years. The government of Fiji estimated that approximately 540,000 people were affected and almost 30,000 houses were destroyed. A severely damaged area during the cyclone was Ba Province, where Navala village is located. The village abounds with Fijian traditional houses called bure. Some bures were destroyed by the cyclone, and the total number of bures has decreased consequent to the introduction of new building materials, such as iron sheeting and concrete. According to a report by the Ministry of iTaukei Affairs, more than half the bures in Navala withstood the cyclone. Therefore, this research aims to observe the impacts of the cyclone on bures in Navala, and identify the disaster response and recovery process of the village community. This research was conducted through a literature review as well as qualitative and quantitative questionnaire surveys on 72 households in Navala. The research results show that the village community cooperates to maintain the bures in ordinary life, and thus could repair them quickly after the cyclone. In addition, they will start self-reconstructing 14 bures this year without outside support and allowances. The questionnaire surveys found that $70 \%$ of the respondents considered bures as safer than modern houses, as the flying iron sheet roofs on modern houses might injure people, while thatched roofs pose no danger. Furthermore, bure collapse slowly, giving time to escape, and even after collapsing, retain the inner space in which to survive. In conclusion, the village community is resistant to cyclones and has the potential for community-based disaster recovery after a cyclone.

Keywords: Republic of Fiji, traditional house, cyclone, disaster response, recovery process, resilience.
\end{abstract}

\section{INTRODUCTION}

\subsection{Background}

The Republic of Fiji (Fiji) is a country prone to cyclones, because of its characteristics as a small island state in the Pacific Ocean. Fiji has an area of 18,333 square kilometers and consists of 332 islands, of which approximately 110 are inhabited. The country's population of 865,611 people mainly resides on the two largest islands: Viti Levu and Vanua Levu. These two islands account for $80 \%$ of the nation land, and house $87 \%$ of the total population. While slightly over half (50.7\%) the population lives in urban areas, the other half lives in rural areas and rely on subsistence farming [1].

On February 20, 2016, Fiji was struck by Tropical Cyclone Winston (TC Winston), the most destructive cyclone in the region in the last 20 years. TC Winston was the first category 5 cyclone to directly affect Fiji. The government of Fiji reported that the damages affected approximately 540,000 people, equivalent to $62 \%$ of the total population. In addition, 30,000 houses were destroyed [2].

Recurring cyclones have placed an enormous burden on the country and its people, causing extensive damage to agriculture, housing, and infrastructure. When small islands 
such as Fiji are affected by natural disasters, recovery and reconstruction take a long time, because of limited resources and geographical isolation [3]. To address the issues of recovery and reconstruction, there is a need to understand the extent of external assistance and identify the challenges and capacity of affected communities for self-recovery.

Cyclones cause extensive damage to housing, and the provision of temporary housing and support for reconstruction are major challenges, especially in rural villages [3]. Most islands have been using new building materials such as iron sheeting and concrete to build their homes. The insufficient materials and few skilful carpenters contribute to delayed housing recovery. This is usually the case for remote islands and inland communities in Fiji. According to interviews with the staff of Fiji Red Cross in March 2017, the recovery of Koro Island is delayed because of the long distance covered to deliver building materials. So that people affected by a disaster can restore their living environment, Fijian traditional houses, called bure, which can be built with locally available resources, are a potential alternative solution for housing recovery [3].

Navala village is one of the villages affected by TC Winston in Ba Province (Fig. 1). It is located along the upstream of Ba River in the highlands of northern-central Viti Levu, the larger of Fiji's two big islands. The village is located approximately $100 \mathrm{~km}$ in road distance from Nadi. The river floods and poor road conditions after heavy rains often limit access to and from the village. Rural villages such as Navala have no choice but to respond to emergency situations themselves. To identify the community-based disaster response and recovery process of the rural village in terms of self-recovery, this paper examines how a village responded during and after TC Winston. Furthermore, the village is known to abound with Fijian traditional houses - bures - and the Ministry of iTaukei Affairs reported that 130 bures are located in Navala, more than half of which withstood TC Winston [1]. This paper also identifies the impact of TC Winston on village housing, especially bures, and explores challenges and their potential to enhance the capacity of people in rural villages to cope with cyclone disasters.

\subsection{Disaster response and recovery}

Self-recovery connects to the concept of resilience, which means the capacity to cope with

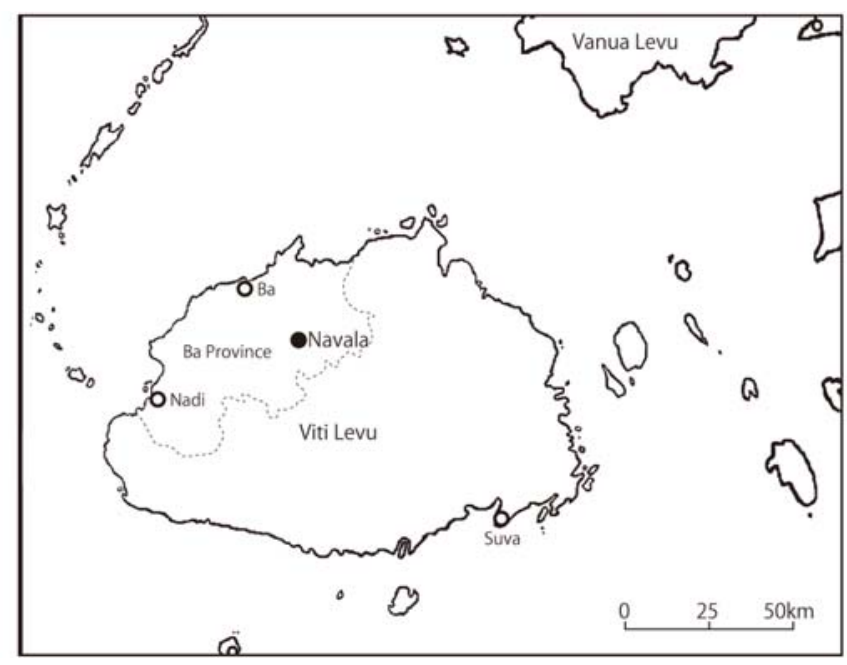

Figure 1: Map of Fiji. 
stress because of the impacts of environmental change [4], and flexibility for reducing the loss and damage after disaster [5]. Resilience can be seen in the culture and social structure of local community, such as bonds, communication, and problem-solving abilities [6]. Adger indicates the access to the resources determined the ability of individual or households to cope with stress [4], and Andrew mentions there is a leader like an interpreter in the resilient community. He or she binds up the community and communicates with the government or informal keypersons. To foster a resilient community, the essential elements of the community are as follows: faith, values, thought of customs, trust, cooperation, strong community, a leader as an interpreter, adaptability [7]. Yoshioka pointed out the mutual aid is the most important element for the resilient community through his study on cyclone disaster in Vanuatu [8]. According to his paper, local people reconstructed their houses quickly by themselves despite no subsidies after the cyclone in Vanuatu.

In this paper, resilience is defined as how quickly community respond to cyclone and how they recover properly by themselves after. The community needs a leader for disaster response, and they require the access to resources and the mutual aid for disaster selfrecovery. This study focused on the disaster resilience in Navala village as a traditional Fijian village which was affected by TC Winston. This research examined how the community responded the cyclone and recovered afterwards, especially focusing on reconstructing bures with local resources.

\subsection{Methodology}

This paper begins with an introduction to Navala village and Fijian traditional houses, and then describes the disaster response and recovery process of the village during and after TC Winston and its impact on housing. The paper concludes by discussing the village's capacity for community-based disaster recovery and the potential of bures as cyclone-resistant houses.

This study is based on several field surveys conducted in Navala village mainly in March 2017. In 2012 and 2013, field surveys were conducted to comprehend the area of the village, to formulate a map of the village, and to identify individual house names. In 2017, the map was remade referring to the list of individual house names. Alongside this, a structured and semi-structured questionnaire survey was conducted in 72 households. The objective of the survey was to understand the extent of damage by TC Winston, how Fijian traditional houses changed after TC Winston hit the village, and villagers' recovery and reconstruction of their village without assistance. Furthermore, key informant interviews were conducted with the village administrator called Turaga ni koro (The village administrator is an elected position in the village and the main task is to carry out government delegated tasks through the district office.) and some men and women of the village.

\section{NAVALA AS A TRADITIONAL FIJIAN VILLAGE}

\subsection{Navala village}

Navala village is located in the highland of Viti Levu Island. The population of the village is 697 people, and there were 140 households in 2017. The village consists of six clans named mataqali. These mataqalis fled and migrated from different areas after tribal wars in the $19^{\text {th }}$ century. Subsequently, in the late $19^{\text {th }}$ century, five villages surrounding the highland agreed to build a school for their children and construct a new village, namely Navala [1]. They constructed streets to form a cross and built a church at the head of the cross. The Fijian 
traditional houses called bures were constructed along the cross street as shown in Fig. 2. Before TC Winston hit the village in 2016, of 140 households, 130 were bures [1].

According to the villagers, the main source of livelihood is small-scale agriculture such as cassava (Manihot esculanta) and yaqona (Pipers methysticum). Furthermore, they earn cash income through tourism and seasonal work in sugarcane plantations. When tourists visit Navala village, they should inform the village administrator and pay the entrance fee (20 Fijian dollars - approximately USD 10 in 2017). In Navala village, a village committee is constituted by the Turaga ni koro (villager leader) and the heads of the mataqalis. The committee manages the village meeting once a month, which all villagers can attend. At the meeting, they discuss community work, village tourism, school management, and so on. Under the village committee is the school committee, women's committee, water committee, health and sanitation committee, and youth committee.

\subsection{Fijian traditional houses: the Bures}

The native Fijians have lived in Fijian traditional houses, named bures, for a long time. Originally, bure meant "community house: or "bedroom for unmarried men" [9]. However, recently, the local people use the term to refer to Fijian traditional houses. There are several types of bure designs unique to each regional village in Fiji. These bures have different forms and are constructed of different material depending on the area. However, all use a timber frame, thatched roof, and thatched wall constructed on the basement called yavu. There are no partitions inside the bure, but a botanical mat is placed on the dirt floor [10] (Fig. 3).

Bures are constructed through community work known as solesolevaki using local materials from the woods in the village. It takes 1-2 months for 10-15 males to construct 1 bure. During the construction in Navala village, laborers gather for solesolevaki three times a week, working on the farms on other days. This system helps to maintain both the bures and villagers' livelihoods, because they can work as farmers while participating in solesolevaki.

When owners need to repair or reconstruct their bures, they apply to the village administrator and discuss the issue with villagers at the village meeting. After the villagers agree, the owners can start with reconstruction. They pay only the transport costs of material and serve food and yaqona to the laborers. In the case of Navala village, if owners cannot afford these costs, they can make a loan from the village committee. The loan is covered by the income from village tourism.

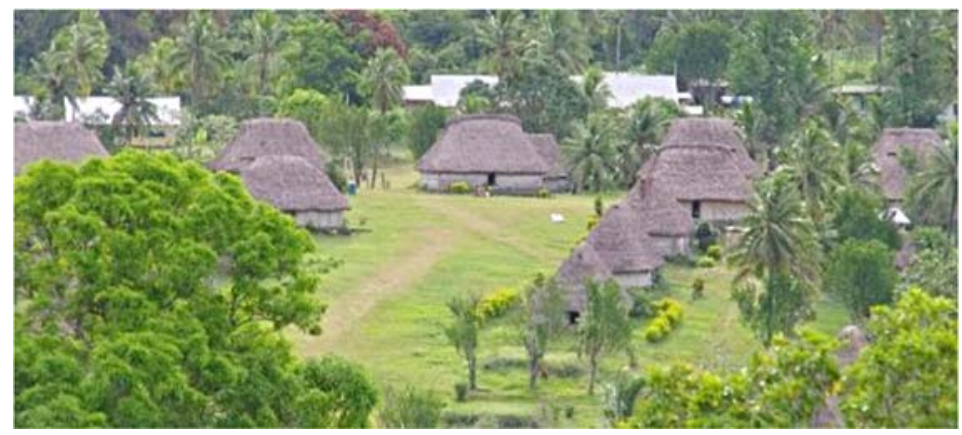

Figure 2: The cross street in Navala village. 


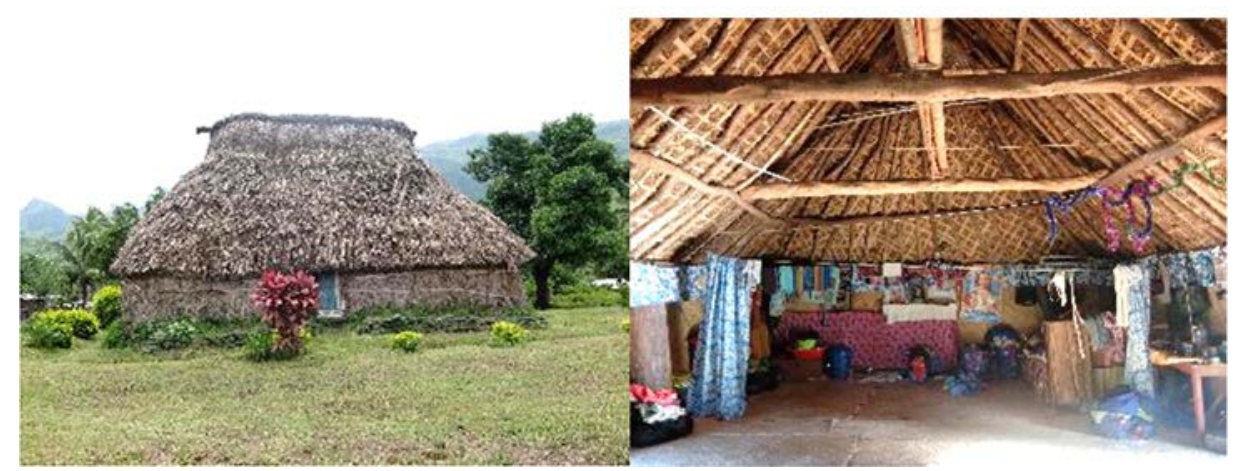

Figure 3: A bure: a Fijian traditional house.

After the British colonized Fiji in 1870, the number of bures decreased consequent to the introduction of new housing materials such as iron sheeting and concrete. Westernization affected the Fijian lifestyle, especially in the 1960s, and the number of bures rapidly declined. In addition, natural disaster is one of the triggers affecting the decline of bures. For example, when TC Bebe hit Fiji in 1972, the number of modern houses drastically increased from 5\% to $45 \%$ in Kabara Island, Lau [11]. In 2016, bure accounted for only $1.9 \%$ of the total housing in Fiji [2].

Navala village boasts more bures than any other village in Fiji. However, the number has been decreasing since 2000 because some of the houses have been reconstructed using new materials, as in other villages in Fiji. The new houses are constructed of concrete blocks or timber frames with corrugated iron sheet roofs. According to the results of interviews with young villagers, the construction of bures became difficult, because of the lack of natural resources and laborers. In 2009, the village committee considered this problem, and decided to preserve the bures along the cross street. Their decision meant that all houses constructed with modern material had to be situated behind the bures.

\section{DISASTER RESPONSE AND RECOVERY PROCESS IN NAVALA VILLAGE}

\subsection{Disaster response}

On the evening of February 20, 2016, TC Winston hit Navala village. The villagers did not receive a cyclone warning before the disaster. Turauga ni koro checked the cyclone track via the radio every day, and informed all villagers verbally of its progress. During the cyclone, $90 \%$ of the villagers, approximately 700 people, evacuated to the school and church. Both are designated evacuation centers in the village. Some villagers evacuated to recently constructed bures, because they considered these strong enough to withstand the intensity of the cyclone. According to the villagers, each bure held four to five households.

The next day, around 200 villagers returned to their houses, which were not seriously damaged; however, 500 evacuees remained at the evacuation centers. The village committee managed the evacuation centers and distributed supplies such as food and water to villagers. The school was opened two weeks after TC Winston, although 12 households remained there for one month in a designated area. 


\subsection{International aid}

After TC Winston passed, some international aid supported recovery in Navala village. Table 1 shows the flow of international aid. Fiji Red Cross investigated the assessment survey and assessed the number of affected households one week after TC Winston hit. They supplied food, bedclothes, and vinyl sheets to affected villagers two weeks later. One month later, aid from China supplied tents and that from New Zealand supplied food through the government of Fiji. Subsequently, UNICEF gave WASH kits (Water, Sanitation, and Hygiene for All) sets to children, tents to the kindergarten, and education sets to the school.

Regarding the reconstruction of houses, the government of Fiji provided a subsidy of 7,000 Fiji dollars (approximately USD 3,400 in 2017) to each of the owners of destroyed houses. However, no villager in Navala has received this subsidy from the government. There was also subsistence of 500-600 Fijian dollars given to members by the Ministry of Social Welfare to support their rehabilitation in the village.

\subsection{Impact of TC Winston on village life}

The questionnaire survey was conducted in Navala village on March 8-15, 2017, to understand the impact of TC Winston on villagers' livelihoods. In total, 72 respondents, accounting for almost $50 \%$ of the total households in Navala village, participated in the questionnaire survey.

The main occupation of 67 of the 72 respondents is farming, mainly the cultivation of cassava and yaqona in the village. Yaqona is a luxury grocery item (e.g., alcohol, coffee, tea) for Fijian people, and cassava and taro (Colocasea esculanta) constitute the main root crops in the Fijian diet. The remaining five respondents worked in the private sector and as civil servants. The income of 48 respondents decreased after TC Winston, because their plantations and crops were severely damaged. On the other hand, the income of 12 respondents increased, because the price of yaqona rose nationally after TC Winston. According to the villagers, the price of yaqona doubled. For these 12, their income averaged 1,056 Fijian dollars per month. On the western side of Viti Levu Island, many farmers cultivate sugarcane outside the villages, and these crops were severely damaged by TC Winston. However, the farmers in Navala village cultivated sugarcane outside the village as well as cassava and yaqona in the village. As such, some villagers were not severely influenced by TC Winston. In addition, self-reconstruction work continues as usual, and must be managed during the working day. As mentioned, the villagers gather for solesolevaki three times a week, and work on their farms on the other days.

Table 1: International aid in Navala village.

\begin{tabular}{|l|l|l|}
\hline When? & Organization & Support \\
\hline \hline One week later & Fiji Red Cross & Assessment survey \\
\hline Two weeks later & Fiji Red Cross & $\begin{array}{l}\text { Supplied food, bedclothes, and vinyl } \\
\text { sheets }\end{array}$ \\
\hline One month later & $\begin{array}{l}\text { China aid } \\
\text { (via the Fiji government) }\end{array}$ & Supplied tents \\
\cline { 2 - 3 } & $\begin{array}{l}\text { New Zealand aid } \\
\text { (via the Fiji government) }\end{array}$ & Supplied foods \\
\cline { 2 - 3 } & UNICEF & $\begin{array}{l}\text { Supplied washing and sanitary sets to } \\
\text { children, tents to the kindergarten, } \\
\text { and education sets to the school }\end{array}$ \\
\hline
\end{tabular}




\section{IMPACT ON THE HOUSES IN NAVALA VILLAGE}

\subsection{Damage caused by TC Winston on houses in Navala village}

As reported by the Ministry of iTaukei Affairs [1], 32 houses were totally destroyed and 30 were severely damaged by TC Winston. Fortunately, there were no deaths in Navala village. This report mentioned the number of damaged houses, but did not reveal which housing type was damaged or the location on the map. Here, the structured and semi-structured questionnaire surveys conducted in March 2017 obtained the following results including the site map. Fig. 4 shows the layout of houses in Navala village and the houses damaged by TC Winston.

Of the total respondents (72) of the questionnaire survey, 58 lived in bures before TC Winston. When the cyclone hit the village, 17 bures totally collapsed; 4 were severely damaged and no longer liveable, as shown in Fig. 5; 3 were severely damaged, but still liveable; 30 were minimally damaged, and 4 were not damaged. One year later, 21 of the 58 bures were completely repaired, and 4 were reconstructed as modern houses. The owners covered the cost of repairs or the reconstruction themselves. Reparations were carried out through communal cooperation, or solesolevaki.

On the other hand, 14 respondents lived in modern houses before the cyclone. Of these, two houses totally collapsed in the cyclone; one was severely damaged, but still liveable; five were minimally damaged; and six were not damaged. According to experts, these damages can be attributed to poor maintenance and the use of new connecting tools (e.g. nails and wires) in construction [1]. According to the Turaga ni koro, they could not see anything during the cyclone, because TC Winston hit the village after sunset and there was no light. This increased the risk of injury for the villagers, who reported hearing iron sheeting blowing around. The villagers who evacuated to the school and church concerned that they would be injured by the iron sheeting carried by the strong wind.

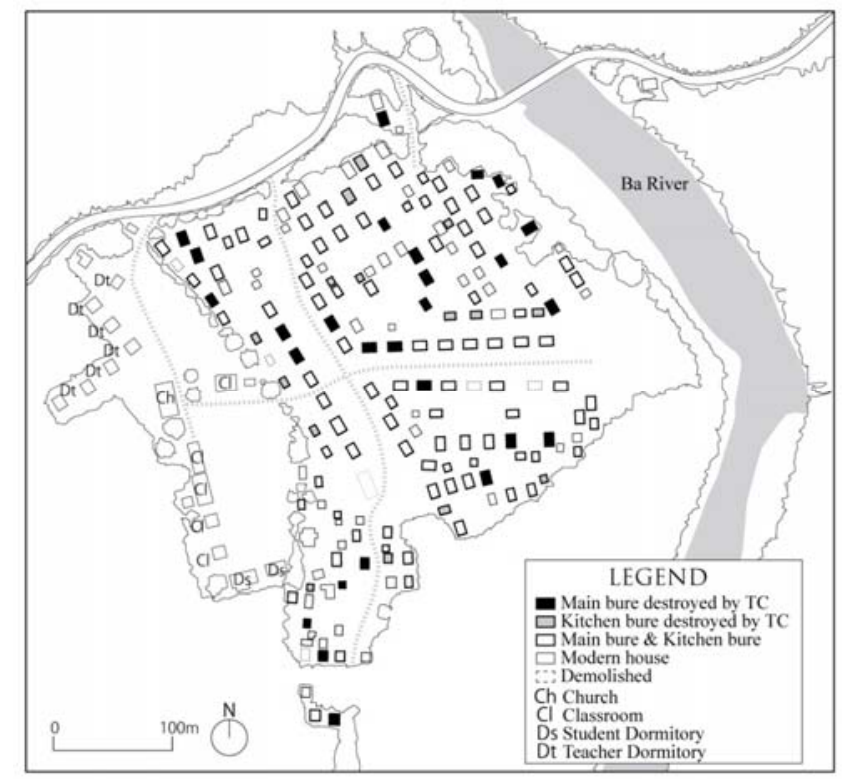

Figure 4: Map of Navala village. 


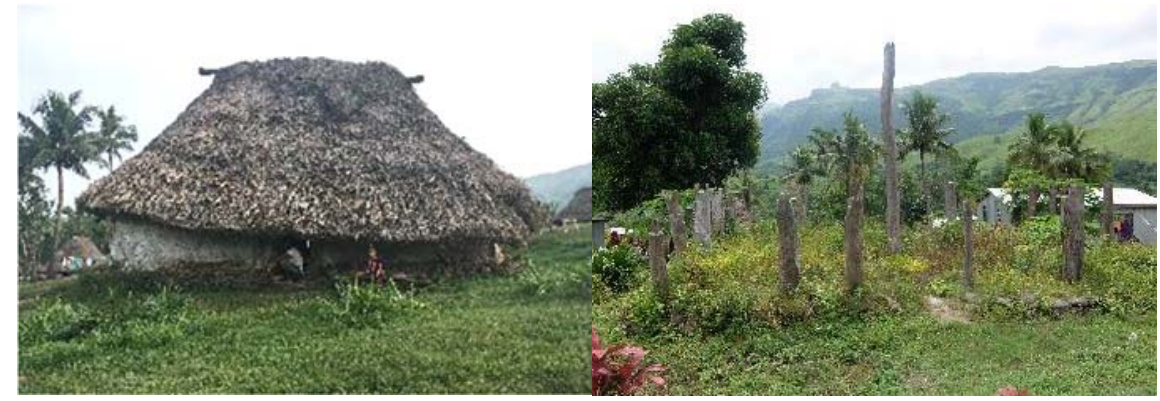

Figure 5: Bures damaged by TC Winston.

\subsection{Disaster recovery}

Despite no subsidy for reconstruction, the village communally conducted the repair of damaged bures. They re-thatched more than 20 bures, and the villagers agreed to start the reconstruction of 14 more through community work in April 2017. The owners of the bures will pay transportation costs and serve food to laborers; however, they do not have to pay the cost of the material because the resources are collected from the woods in the village. On the other hand, the owners of modern houses paid the cost of material and hired carpenters when they started reconstructing their houses.

During the reconstruction of the bures, villagers stayed in tents and other temporary arrangements, usually in the kitchen, a relative's house, or temporary houses. There are two types of temporary houses: 1) Those constructed from new materials (Fig. 6: left) including a timber frame, bamboo or iron sheeting wall, and iron sheeting roof; and 2) those constructed from natural resources (Fig. 6: right) such as a timber frame, bamboo wall, and thatched roof. Both were constructed in-situ by owners and relatives within three to seven days.

\subsection{The current situation of bures in Navala village}

In Navala village, each household uses other buildings such as the kitchen behind the main house, which is used as a bedroom. Some kitchen buildings are bures; however, this study focuses on the main housing bures. Table 2 provides the results of the field survey, showing the number of houses before and after TC Winston. In 2015, before TC Winston, there were

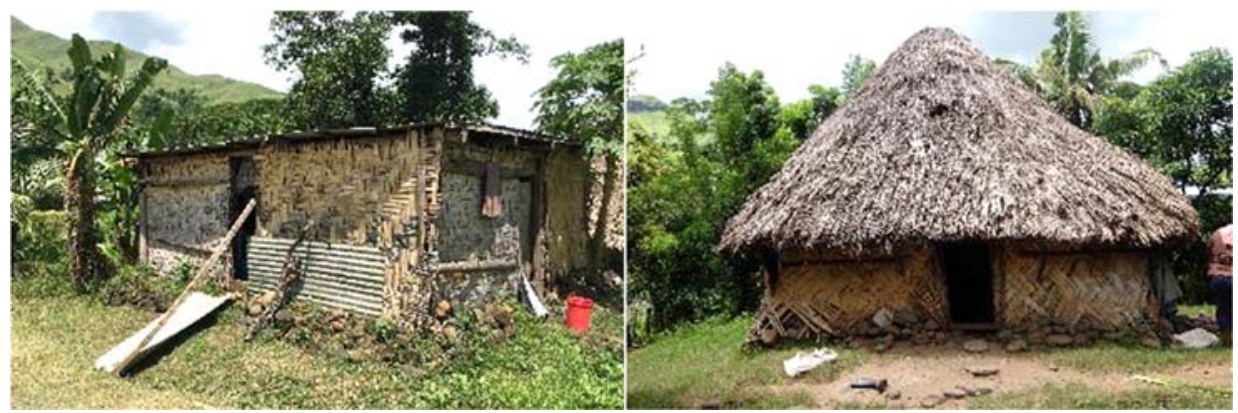

Figure 6: Temporary houses using new materials (left) and natural resources (right). 
99 bures, which accounted for $75 \%$ of the total 132 houses. However, the survey in 2017 confirmed 72 liveable bures of the total 136 houses after TC Winston. Over the last two years, 26 bures have disappeared, mainly because of destruction by the cyclone. One bure was reconstructed as a modern house before TC Winston. In 2017, one year after TC Winston, 20 temporary houses were constructed besides the yavu, and 4 were reconstructed using new materials.

The village community repaired damaged bures in 2016, and the village committee decided to start the reconstruction of 14 bures in April 2017, despite no allowance from outside sources.

\subsection{Attitude towards bure as disaster-resistant houses}

The questionnaire survey revealed the attitude towards bures as disaster-resistant houses. Respondents (a total of 72) were asked what type of house they considered safer. Three options were provided: "Fijian traditional house," "modern house," and "both" (indicating that both are safe or not safe). The results show that 50 respondents considered as safer the "Fijian traditional house," 10 respondents considered a "modern house" safer, and 11 respondents considered "both" as safer (Fig. 7). Respondents were then asked their opinion on whether a bure would withstand a cyclone. This question provided five options as follows: "very weak," "weak," "neutral," "strong," and "very strong." They were asked for their opinion regarding this question for the period before TC Winston and after the cyclone. In total, 39 respondents stated their opinion as "strong" for the period after TC Winston, while 41 thought "strong" too at the time before TC Winston. In addition, 19 respondents considered them "very strong" in the period after TC Winston, and 21 thought "very strong" before TC Winston. Interviewees regarded bures as strong for the following reasons: "The flying iron sheeting of the roofs of the modern houses might be easily blown away and injure people, whereas thatched roofs pose no danger," and "bure collapse slowly, giving time to escape, and they retain the inner space where one can survive, even after collapsing." On the other hand, some respondents ( 14 after TC Winston and 10 before) do not believe that bures can withstand a cyclone, because they think old bures weaken and will not be strong enough in a disaster.

One question asked 22 of the 72 respondents whose houses collapsed or were totally destroyed: "Which house type did or will you reconstruct?" Three options were provided for this question: "Fijian traditional house," "modern house," and "mixed house." The results show that 17 of the 22 respondents will reconstruct a "Fijian traditional house." The decision for reconstruction lies with the village committee, who then confirm during the village

Table 2: Number of houses in Navala village before and after TC Winston.

\begin{tabular}{|l||l|l|l|}
\hline & $\begin{array}{l}\text { Before the cyclone } \\
\text { (April 2015) }\end{array}$ & $\begin{array}{l}\text { After the cyclone } \\
\text { (May 2017) }\end{array}$ & The reason the number of houses changed \\
\hline \hline Total number & 132 & 136 & 4 houses: households were increased \\
\hline Bures & 99 & 72 & $\begin{array}{l}\text { 26 bures: destroyed by TC Winston. } \\
\text { (20 houses: temporary houses, } \\
4 \text { houses: modern houses, } \\
\text { 2 houses: not reconstructed) } \\
\text { 1 bure was transformed from a bure to a } \\
\text { modern house before TC Winston } \\
\text { houses } \\
\text { modern houses were newly built for } \\
\text { newly married couples }\end{array}$ \\
\hline
\end{tabular}




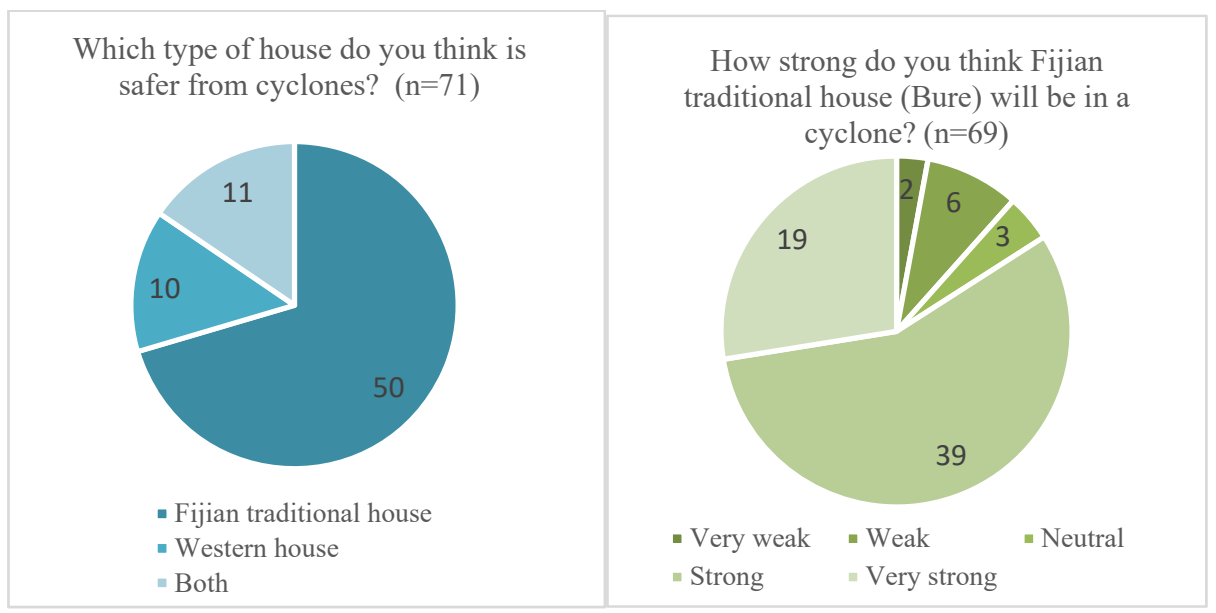

Figure 7: The results of the questionnaire survey.

meeting the timing of reconstruction. The results cannot reveal the additional respondents who chose to begin reconstruction on the bure on their own or those who will wait until the next community work scheduled in 2018. The remaining five respondents chose "modern house" and "mixed house," using the subsidy they received by choosing not to wait for the community work to be decided at the village meeting.

\section{DISCUSSION}

Based on the analysis of the results of the field survey, the village community is resilient to cyclones to a certain extent. The following discussions are the elements of resilience in Navala village and challenges for enhancing the resilience.

\subsection{Community-based disaster response and recovery}

In Navala village, the Turaga ni koro and village committee managed the evacuation center after TC Winston. They made decisions regarding food distribution and rapid response after the cyclone (e.g. rebuilding toilets, clearing debris, water collection, etc.). This indicates that the village committee is well organized and can work in cohesion with the community, as they have gained the villagers trust. This was also possible because the decision-making system of the village committee was effective through their community activities in ordinary times. It can be concluded that the community responded properly following the Turaga $n i$ koro and the village committee during the cyclone.

\subsection{Community-based disaster recovery}

One year later, the villagers have already started repairs on the houses without receiving outside subsidies. Furthermore, they have decided to start the reconstruction of 14 bures in April 2017 of the homes that were destroyed. They can repair and reconstruct their bures quickly, because they have been maintaining them consistently over time. In addition, the loan system of reconstruction can be a safety net for affected villagers after a cyclone. However, several of the destroyed bures will be not be reconstructed in 2017. It is uncertain whether the owners will wait for the reconstruction or reconstruct them as modern houses. 
Altogether, 200 males work as laborers in Navala village, limiting the number of reconstruction projects that can be undertaken in one year. It can be said that the community has a certain resilience for disaster recovery by themselves, but their capacity is limited and it is difficult to reconstruct more than 14 bures in the same year.

\subsection{The potential of bures as cyclone-resistant houses with local resources}

The community repaired the damaged bures and will start to reconstruct the destroyed bures with local resources because they have their own woods near the village. In addition, the bures have the potential as cyclone-resistant houses. It is because some villagers evacuated to bures during the cyclone, as they regarded them strong enough to withstand the cyclone. Considering this, bures can potentially be established as evacuation centers. In addition, the results of the questionnaire survey show that most villagers regard bures as safer than modern houses because new bures withstood during the cyclone and they retain the inner space where one can survive, even after collapsing, and the villagers agree that iron sheeting might be dangerous during a cyclone. This is one reason they maintain and reconstruct bures. On the other hand, some think that old bures could be easily destroyed in a cyclone if they are not properly maintained. Thus, bures should be maintained properly at the stated periods.

\section{CONCLUSION}

The field survey results indicate that Fijian traditional houses, or bures, are resilient to disasters. Navala village has an effective governance system wherein the village committee coordinates rehabilitation activities after a disaster, because the houses (bures) are maintained through community work (solesolevaki). The villagers regard bures as safer than modern houses when they are maintained and properly reconstructed. In addition, bures can potentially avoid the risk of injuries, because they have ample inner space. This research supports the findings of other studies and reports, which state that by having traditional houses, communities can quickly recover and rehabilitate after a cyclone [3], [12]. In addition, the results of community-based recovery can contribute to other affected villages such as remote villages and islands, because it takes a long time to deliver supplies after cyclones in such areas. On the other hand, when the large-scale cyclone hit the village, many bures collapsed; however, it was difficult to collect enough laborers for solesolevaki to reconstruct them all at the same time. In terms of quick disaster recovery, villagers can use new materials, which are helpful for reconstruction. Thus, a scenario considering appropriate, rapid recovery is needed.

Further research can be undertaken to examine the livelihood of the community and how it was affected after TC Winston. Comparative studies can be conducted with other affected communities in Fiji to measure the rate of recovery in a community with a higher number of modern houses. This will also allow further investigation on effective community structure and systems for disaster recovery.

\section{ACKNOWLEDGEMENTS}

The community of Navala Village made enormous contribution to the field survey. This work was supported by JSPS KAKENHI Grant Number JP 16H05630.

\section{REFERENCES}

[1] Itaukei Institute of Language and Culture and Ministry of Itaukei Affairs, Navala Pdna Report, 2016. 
[2] Government of Fiji, Post-disaster needs assessment: Tropical Cyclone Winston, 20 Feb. 2016.

[3] Fujieda, A. \& Kobayashi, H., The potential of Fijian traditional housing to cope with natural disasters in rural Fiji. Journal of Disaster Research, 8(1), pp. 18-27, 2013.

[4] Adger, Social and ecological resilience: are they related? Progress in Human Geography, 24(3), pp. 347-364, 2000.

[5] Hyogo Earthquake Memorial $21^{\text {st }}$ Century Research Institute, Handbook of disaster management, Gyousei: Japan, 2011-2015.

[6] Masaki Urano et al., Introduction of the theory of post-disaster community recovery, Koubundou: Japan, 2007.

[7] Zolli, A. \& Henry, A.M., Resilience - Why Things Bounce Back, Simon and Schuster: USA, 2013.

[8] Yoshioka, M., Toward the resilience on Anthropology: The case of Cyclone disaster in Vanuatu, Japanese Society for Oceanic Studies, 115, 2017.

[9] Tipett, A.R., Fijian Material Culture - A study of Cultural Context, Functional and Change, Bernice P. Bishop Museum Bulletin 232, Bishop Museum Press: Honolulu, Hawaii, pp. 143-144, 1968.

[10] Kobayashi, H. \& Fujieda, A., Research on indigenous building technology of Fijian traditional wooden houses - Bure - Case study on the bure construction project of CATD, Journal of Architectural Planning, AIJ, 81(724), pp. 1303-1313, 2016.

[11] Bayliss-Smith, T., Bedford, R., Brookfield, H. \& Latham, M., Islands, Islanders and the World: The colonial and post-colonial experience of eastern Fiji, Cambridge University Press: England, 1988.

[12] UNDRO, Shelter after disaster guidelines for assistance, United Nations, New York, 1982. 